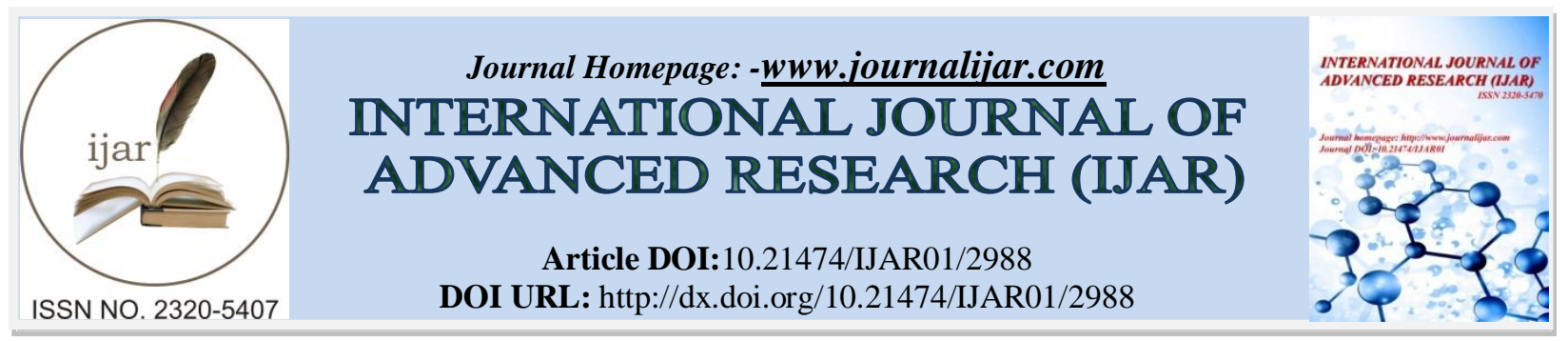

RESEARCH ARTICLE

\title{
EVALUATION OF CD9 \& CD56 ANTIGENS EXPRESSION IN ADULT ACUTE MYELOID LEUKAEMIA.
}

Dr. Subh S. Al-Mudallal, Dr. Hind Shaker Al-Mamoori and Dr. AlaaShamikh Hassan

\section{Manuscript Info}

Manuscript History

Received: 28 November 2016

Final Accepted: 27 December 2016

Published: January 2017

\begin{abstract}
Background: -Acute myeloid leukaemia (AML) is a malignant clonal disorder resulting from the neoplastic proliferation of a clone of myeloid cells. Flow cytometry is used for confirming diagnosis, identifying prognostic differences, staging of $\mathrm{AML}$ and detecting an aberrant immunophenotype that can be used for monitoring of complete remission $(\mathrm{CR})$ achievement.

Objectives: - To evaluate the expression of aberrant CD9 and CD56 in newly diagnosed adult AML patients and their association with clinical and haematological parameters and with CR achievement.

Methods: -Thirty adult patients $(>15$ years) who were newly diagnosed de novo AML were selected from the Baghdad Teaching Hospital andAl- ImameinKadhimein medical cityfrom July 2015 to March 2016. All patients were grouped according to FAB classification and evaluated individually and the diagnosis was based on the morphology, cytochemistry or flow cytometry. Aberrant antigens CD9 and CD56 expressions were investigated by four- colours flow cytometry at the time of diagnosis. The patients were evaluated at day 28 from the start of chemotherapy to assess complete remission achievement. Verbal consent was taken from the patients.

Results: -The aberrant expression of CD56, CD9 were observed in $23.3 \%$ and $33.3 \%$ of AML patients respectively. CD56 was expressed more with monocytic differentiation and CD9 was expressed more with M2 cases. CD56 expression was significantly associated with high total WBC count, high peripheral blood and bone marrow blast cells and the extramedullary manifestations. There was significant association between CD56 and CD9 expression regardless of their intensity of the markers with non-responsiveness to induction therapy.

Conclusion: -Aberrant CD9 and CD56 antigens were associated with adverse clinical and hematological parameters at presentation as well as with low cure rate.

Copy Right, IJAR, 2016,. All rights reserved.
\end{abstract}

\section{Introduction: -}

Acute myeloid leukaemia (AML) is a hematopoietic stem cell disorder, characterized by a block in differentiation of haematopoiesis which results in the growth of a clonal population of neoplastic cells or blasts. This malignant alteration in hematopoietic stem cells leads to a loss of normal hematopoietic function. The peak incidence rate 
occurs in the first year of life and then decreases steadily up to the age of 4 years and remains relatively constant in childhood and early adulthood; AML is thus a disease of adults. (1)

AML represents approximately $90 \%$ of all acute leukemias in adults but accounts for only $13 \%$ of leukaemia cases in children younger than 10 years.(2)

Recurring chromosomal aberrations and gene mutations are frequently found in AML and contribute greatly to the pathogenesis of the disease. (2) One of these is the $t(8 ; 21)$ (q22; q22) translocation which produces RUNX1RUNX1T1 fusion product that blocks hematopoietic differentiation and enhances self-renewal of hematopoietic stem cells.

The inv (16) (p13q22) or $\mathrm{t}(16 ; 16)(\mathrm{p} 13 ; \mathrm{q} 22)$ produces the leukaemogenicCBFß-MYH11 fusion gene which blocks differentiation of hematopoietic stemcells by inhibiting the function of Runt-related transcription factor 1 (RUNX1).APL cells usually have t(15;17)(q22;q11-21) producing PML-RARA fusionproducts which also behave as a transcriptional repressor.

Accurate diagnosis and classification in AML are essential for treatment decisions and assessment of prognosis. Initial assessment requires a careful history, physical examination, complete blood count (CBC) with peripheral blood (PB) smear review, bone marrow (BM) examination, Flow cytometry (FC), cytogenetic and selected molecular genetic analysis. (3)

Classification of AML: -

Acute myeloid leukaemia can be classified in many ways: $(4,5)$

1. By morphology and cytochemistry supplemented by immunophenotyping, asproposed by the FAB group.

2. The morphologic, immunologic, and cytogenetic (MIC) classification, whichwas the first to recognize the usefulness of cytogenetic for identifyingsubgroups of acute leukaemia.

3. The WHO Classification which takes into account morphologic andimmunologic features plus well-studied, common non-random chromosomalabnormalities.

4. By immunophenotyping alone, as proposed by the European Group for theimmunological classification of leukaemias (EGIL).Laboratory investigation of acute myeloid leukaemia:

\section{CBC and peripheral blood Smear: -}

The leukocyte countis elevated in more than one half of patients but is $>100,000$ cells $/ \mathrm{mm} 3$ in $<20 \%$. Blasts usually are identified on peripheral smear; Auer rods are consideredpathognomonic of AML (which are reddish rod-like filaments of aggregatedprimary granules). A leukemic leukemia (no blasts in the peripheral smear) israre. (6)

\section{BM Morphology: -}

A bone marrow aspirate is part of the routine diagnostic work-up of a patientwith suspected AML. A marrow trephine biopsy is optional, but it should beperformed in patients with a dry tap. For a diagnosis of AML, a marrow orblood blast count of $20 \%$ or more is required, except for AML with $t(15 ; 17), \mathrm{t}(8 ; 21)$, inv $(16)$ or $\mathrm{t}(16 ; 16)$. Myeloblasts, monoblasts, and megakaryoblasts areincluded in the blast count. In AML with monocytic or myelomonocyticdifferentiation, monoblasts and promonocytes, but not abnormal monocytes, arecounted as blast equivalents.Erythroblasts are not counted as blasts except in therare instance of pure erythroid leukaemia. (7)

\section{Cytochemistry: -}

Cytochemistry encompasses the techniques used to identify diagnosticallyuseful enzymes or other substances in the cytoplasm of haemopoietic cells

A: Myeloperoxidase: Myeloperoxidase is a lysosomal enzyme present ingranulocytic and monocytic cells. The basis of the stain is breakdown ofhydrogen peroxide by the enzyme MPO.

B: Sudan Black B (SBB) stain: which is a lipophilic dye that binds irreversibly to an undefined granule component in granulocytes, eosinophils and some monocytes. The intensity of a positive reaction with SBB in general parallels MPO activity; however, SBB is preferable as it is slightly more sensitive in the detection of myeloblasts. (8) 
C: Specific esterases: Specific Esterases are a group of enzymes capable ofhydrolyzing halogenated naphthol esters. The most commonly used substrateis naphthol AS-D chloroacetate. Chloroacetate esterase (CAE) is mostfrequently used for the identification of neutrophilic series; it is negative formonocytes, megakaryocytes, erythroblasts and lymphocytes. (8)

D: Nonspecific esterases: are a group of enzymes capableof hydrolyzing various aliphatic and aromatic short chain esters. The substrates used to detect NSEs activity include $\alpha$-naphthyl butyrate, $\alpha$-naphthyl acetate, naphthol AS-D acetate and naphthol AS acetate. they are most frequently used because they do not stain for granulocytes. Beside monocytes and histiocytes, $\alpha$-naphthyl acetate esterase is also positive in megakaryocytes and platelets. (9)

E: Periodic Acid-Schiff (PAS) Reaction: Periodic acid specifically oxidizes 1-2glycol groups to produce stable aldehydes which give a red reaction productwhen exposed to Schiff's reagent (leucobasic fuchsin). A positive PAS stain inerythroblasts is a common finding in erythroleukemia where it has a coarselygranular pattern in cells of early stage and a finely granular pattern in cells oflater stage. (9)

\section{Immunophenotyping:-}

Leukaemic cells express characteristic nuclear, cytoplasmic and cell surface antigens, this is referred to as the immunophenotype of the cell. Characterization of the immunophenotype is referred to as immunophenotyping is achieved by means of labeled antibodies that recognize specific epitopes of cellular antigens by:

A: immunocytochemistry methods.

B: multiparameter immunophenotypic flow cytometry.

Flow cytometry is the measurement of numerous cell properties as the cells move in single flow in a fluid column and interrupt a beam of laser light. The method allows the quantitative and qualitative analysis of several properties of cell populations from body fluids. In an individual patient, the role of Flow cytometric (FC) immunophenotyping may be: confirming a diagnosis, identifying prognostic differences within a diagnostic category, staging a disease, and detecting an aberrantimmunophenotype that can be used for monitoring minimal residual disease, i.e. expression of an antigen inappropriate to a lineage. (10)

Leukaemic myeloblasts express a variety of leucocyte differentiation antigens, which reflect commitment to the myeloid lineage as well as a level of maturation. In the EGIL classification, AMLs are defined immunologically by the expression of 2 or more of the following myeloid markers: MPO, CD13, CD33, CDw65, and CD117. (11) as shown in (Table 1).

Table 1:- Expression of cell-surface and cytoplasmic markers for thediagnosis of acute myeloid leukemia. (7)

\begin{tabular}{|c|c|}
\hline Myeloid stage & CD markers \\
\hline Precursor stage & CD34, CD38, CD117, CD133, HLA- DR \\
\hline $\begin{array}{c}\text { Granulocytic } \\
\text { markers }\end{array}$ & CD13, CD15, CD16, CD33, CD65, cytoplasmic myeloperoxidase (cMPO). \\
\hline Monocytic markers & $\begin{array}{c}\text { Nonspecific esterase (NSE), CD11c, CD14, CD64, } \\
\text { Lysozyme, CD4, CD11b, CD36, NG2 homologue. }\end{array}$ \\
\hline Megakaryocytic markers & CD41 (glycoprotein IIb/IIIa), CD61 (glycoprotein \\
& IIIa), CD42 (glycoprotein 1b). \\
\hline Erythroid marker & CD235a (glycophorin A) \\
\hline
\end{tabular}

Aberrant immunophenotyping expression: -

In the majority of cases of AML, leukemia cells have immunophenotypethat distinguish them from myeloid progenitor cells found in normal marrow.Comparison of antigen expression on AML cells with that in normal bonemarrow reveals: (a) expression of non-myeloid antigens; (b) asynchronousexpression of myeloid-associated antigens; (c) over expression of myeloidassociatedantigens; and (d) absence of expression of myeloidassociatedantigens. (12)

\section{CD9:-}

A transmembrane-4 super family that are characterized as having four transmembrane domains withcytoplasmic $\mathrm{N}$ and $\mathrm{C}$ termini and the conserved cysteine motif, which act as "molecular facilitators" and linkers for 
transmembraneproteins forming tetraspaninweb.(13)

CD56:-

CD56 antigen, a 200-220-kDa cell surface glycoprotein, belongs to theimmunoglobulin supergene family and has been identified as an isoform of theneural cell adhesion molecule (NCAM). This antigen mediates cell-tocellinteractions and is possibly involved in cell-mediated cytotoxicity. (14)

Aims of the study:-

1. To detect the frequency of aberrant CD56 and CD9 expression in denovo newly diagnosed cases of adult AML.

2. To evaluate the correlation of CD56 and CD9 expression with certainclinical and haematological parameters and their initial response to theinduction therapy.

Patients, Materials and Methods:-

This prospective cross-sectional study was conducted on thirty adults newlydiagnosed de novo AML patients from July 2015 to March 2016.

The patients were admitted to the Hematology Department of BaghdadTeaching Hospital of the Medical City and Al- ImameinKadhimein medical city.Diagnosis was based on morphology and cytochemistry of the PB and/or BMAsamples by an expert haematopathologist in the Teaching Laboratories of theMedical City in Baghdad and AlImameinKadhimein medical city. FC was doneby four-color (PartecCyflow®, Germany).

\section{Flow cytometric Immunophenotyping:-}

After AML cases have been documented in the Teaching Laboratories, thesamples were transferred in cool box (6 hours being the maximum time sinceobtaining the sample) to be investigated for the aberrant expression of surfacemarker antigens CD56 and CD2 by using four-color (PartecCyflow ${ }^{\circledR}$ Cube 6, Germany).

Gating of the cells of interest was done depending on FSC/SSC gate. Devicesoftware based on Windows ${ }^{\mathrm{TM}} \mathrm{FC}$ software $\left(\mathrm{CyView}^{\mathrm{TM}}\right)$, and the optics of theinstrument employing 6 optical parameters: FSC and SSC work in combinationwith 4 fluorescence channels (FL1-FL4). (15)

\section{Assay Procedure:-}

Includes 3 steps:-

1. Antibody labeling: $100 \mu \mathrm{l}$ of whole blood was mixed with $10 \mu \mathrm{l}$ conjugatedantibodies in a test tube, and after thoroughly mixing the mixture was incubated for 15 minutes in the dark at room temperature.

2. Leucocyte fixation: $100 \mu \mathrm{l}$ of reagent A was mixed thoroughly with the mixtureobtained in step 1 and was incubated for 10 minutes in the dark at roomtemperature.

3. Erythrocyte lysis: $2.5 \mathrm{ml}$ of reagent $\mathrm{B}$ was added to mixture in step 2 and wasshaken gently and incubated for 20 minutes in the dark.

Determination of the aberrant markerIdentification of blast cells was performed using FSC versus SSC parameters. Basically, antigen expression is considered to be positive when the percentage ofpositive blast cells is equal or greater than $20 \%$. Similarly, aberrant phenotypes aredefined when at least $20 \%$ of the blast cells expressed that particular phenotype. (16)(Figure 1, 2, 3).

\section{Statistical Analysis:-}

Statistical Package for Social Science (SPSS) version 17 was used to present, describe and analyze data included in the present study. Numeric variables werepresented as mean and standard deviation. Nominal variables were expressed as frequency (number) and percentage out of total. Pearson's chi-square and Fisher exact tests were used to evaluate nominal variable frequency difference between groups. Independent sample student t-test was used to compare the mean of numeric variables between groups. The level of $(\leq 0.05)$ was considered significant for interpretation of $\mathrm{P}$ values. 

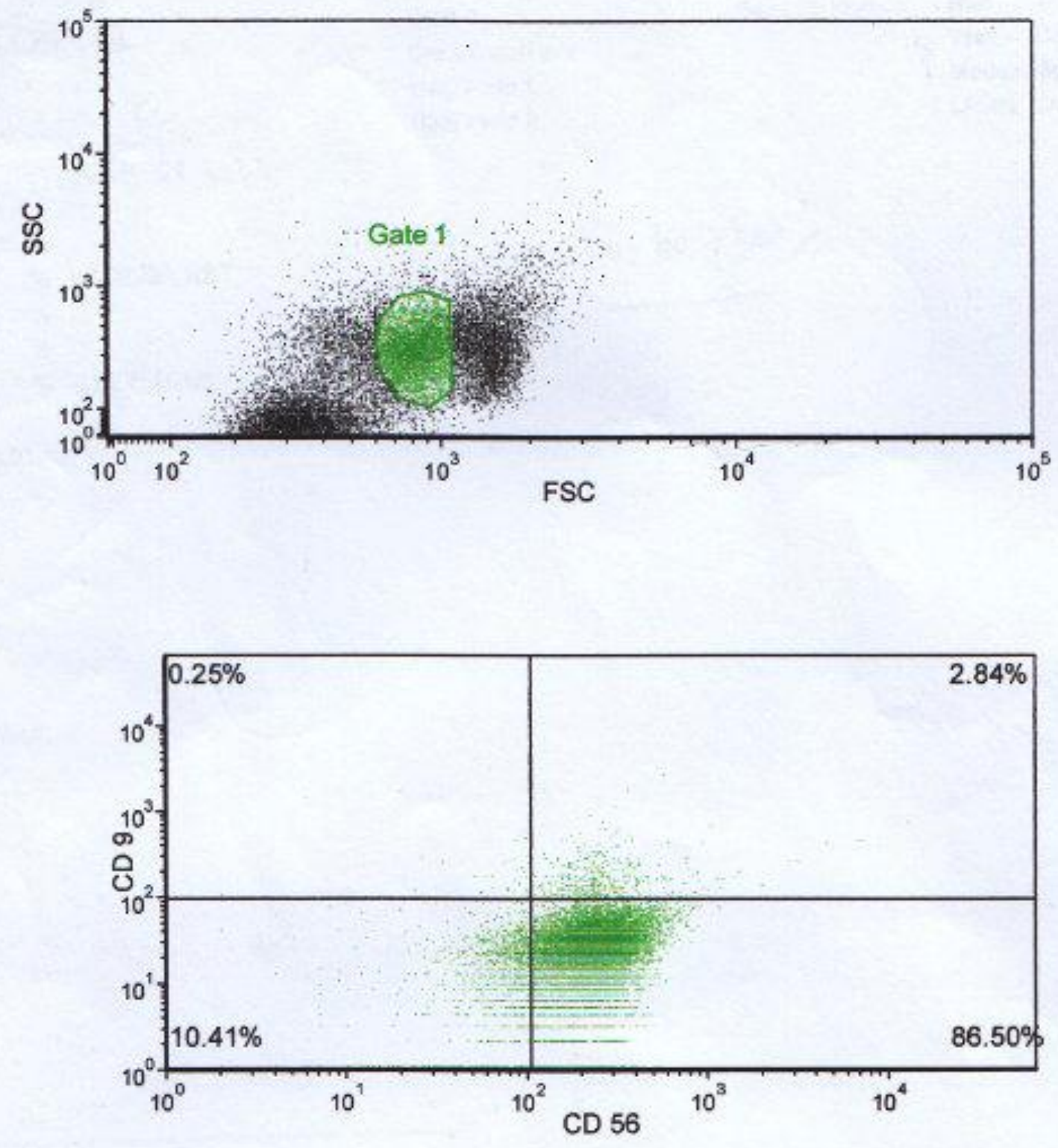

Figure.1:- Aberrant expression of CD56 by FC 

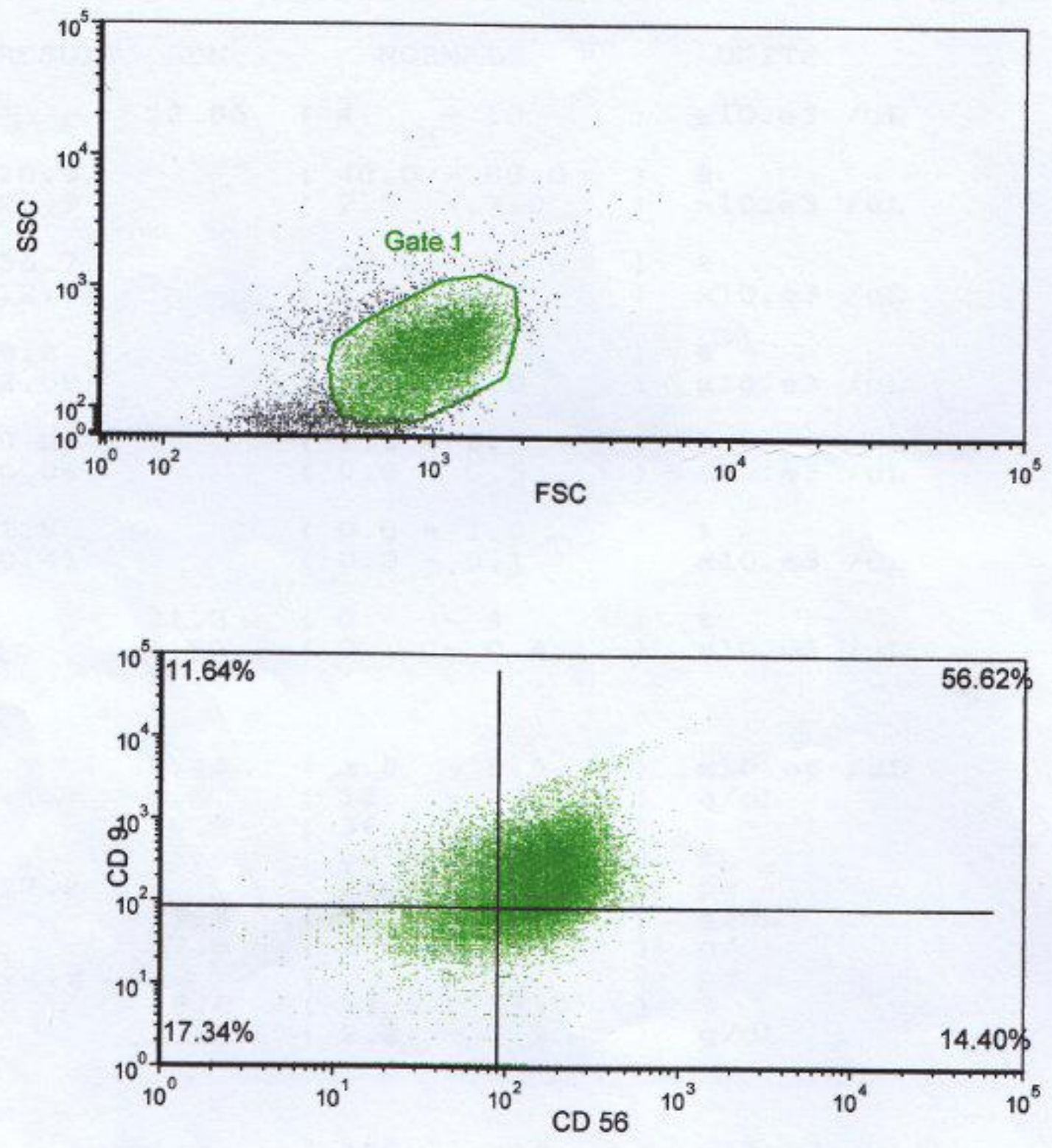

Figure 2:- Aberrant co-expression of CD56 and CD9 by FC 

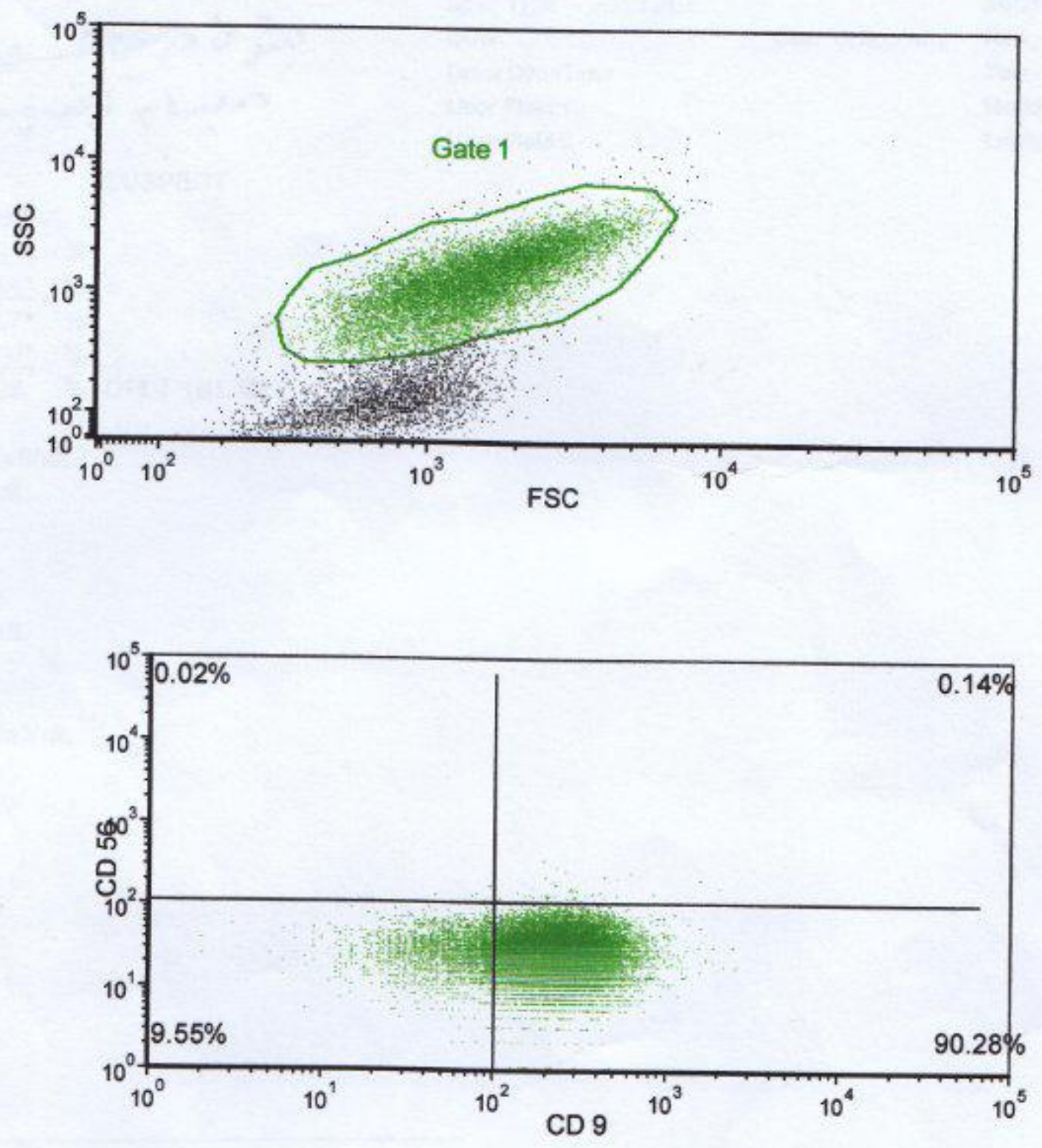

Figure 3:- Aberrant expression of CD9 by FC

\section{Results:-}

Age Groups:-

The mean age of AML patients included in this study was 41.33 \pm 16.6 SD, with a median of 38 years (range of 1675 years). Half of the cases (50\%) beingin the age group 21-40 years (Figure 4 ). 


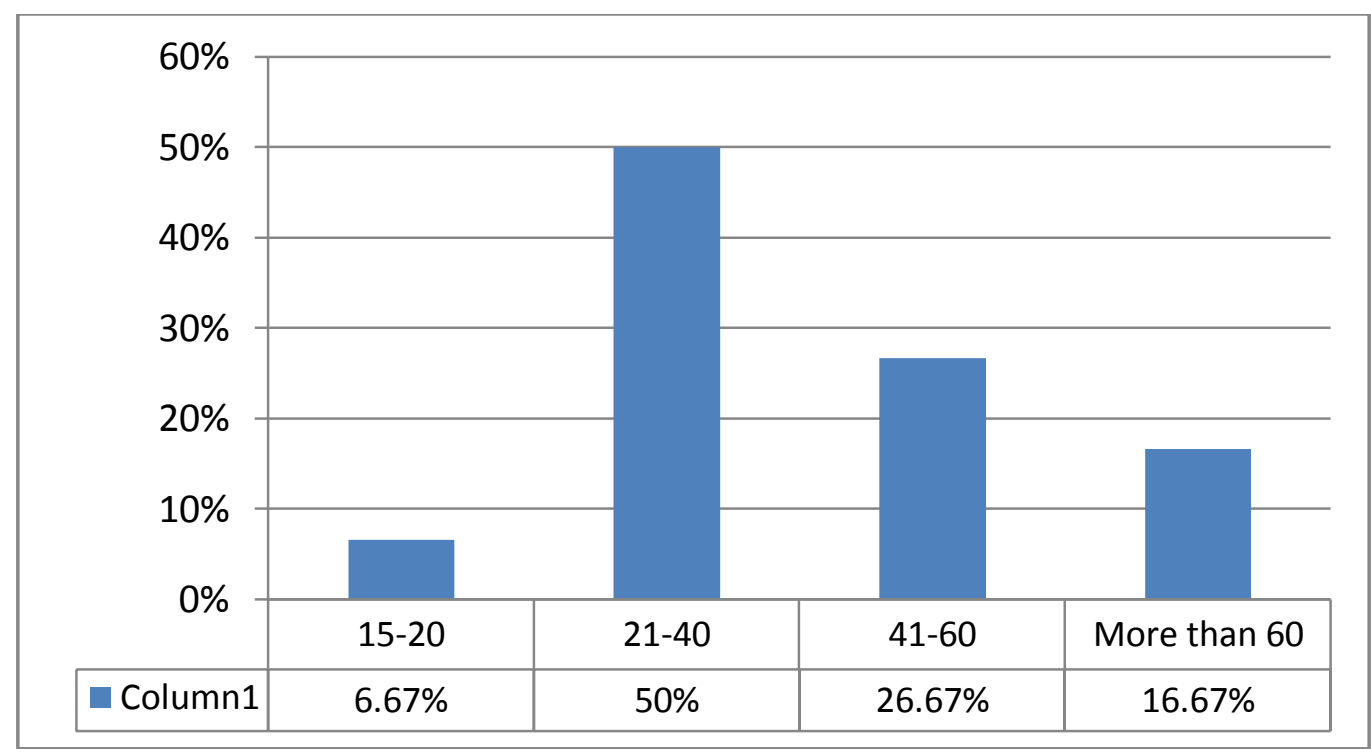

Figure 4:- Distribution of the patients according to the age groups.

\section{Gender:-}

Acute myeloid leukaemia were observed more in males (17 males " $56.7 \%$ \%)than in females (13 females " $43.3 \%$ ") with an M: F ratio of 1.3:1.

\section{Distribution of AML cases according to the FAB subtypes:-}

According to FAB subtypes, of the 30 cases studied, 4 were M1, 9 were M2,7 were M3, 4 were M4, 4 were M5, one was M6 and one was M7. (Figure 5)

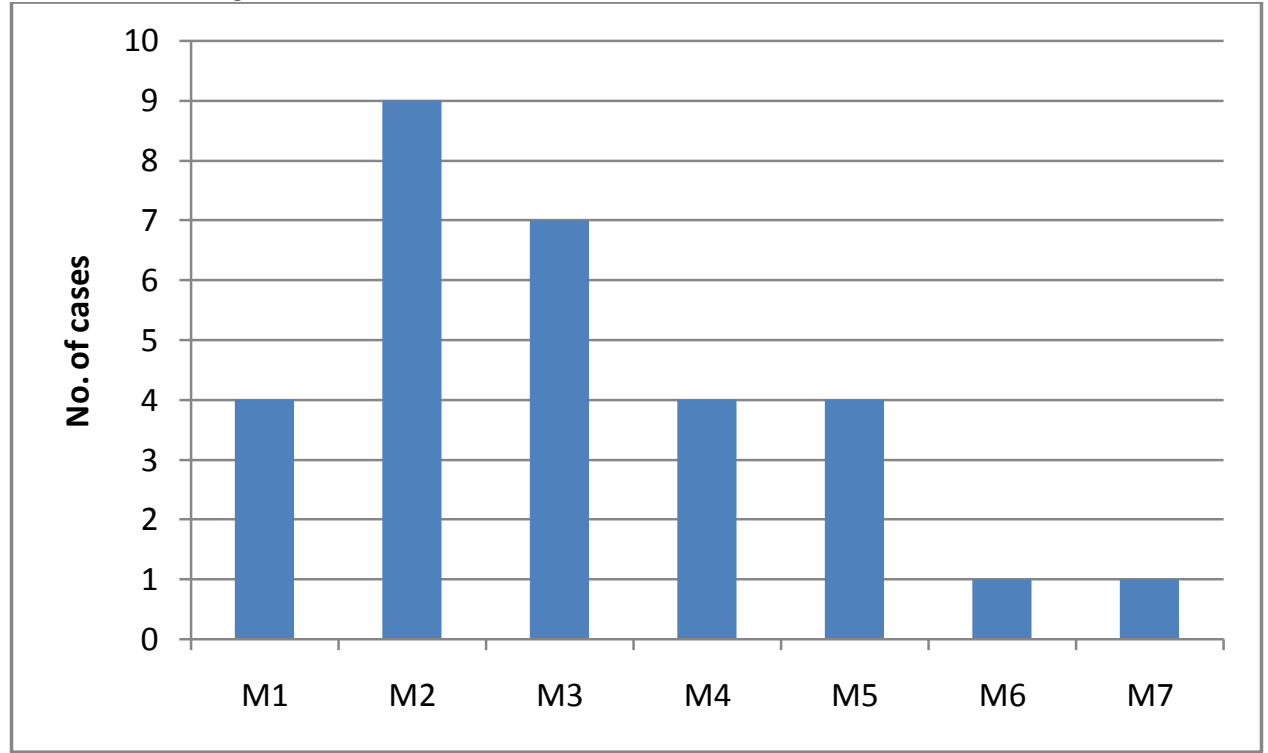

Figure 5:- Distribution of patients according to FAB subtypes 


\section{Clinical Features:-}

Figure 6:- shows the common signs and symptoms of AML patients

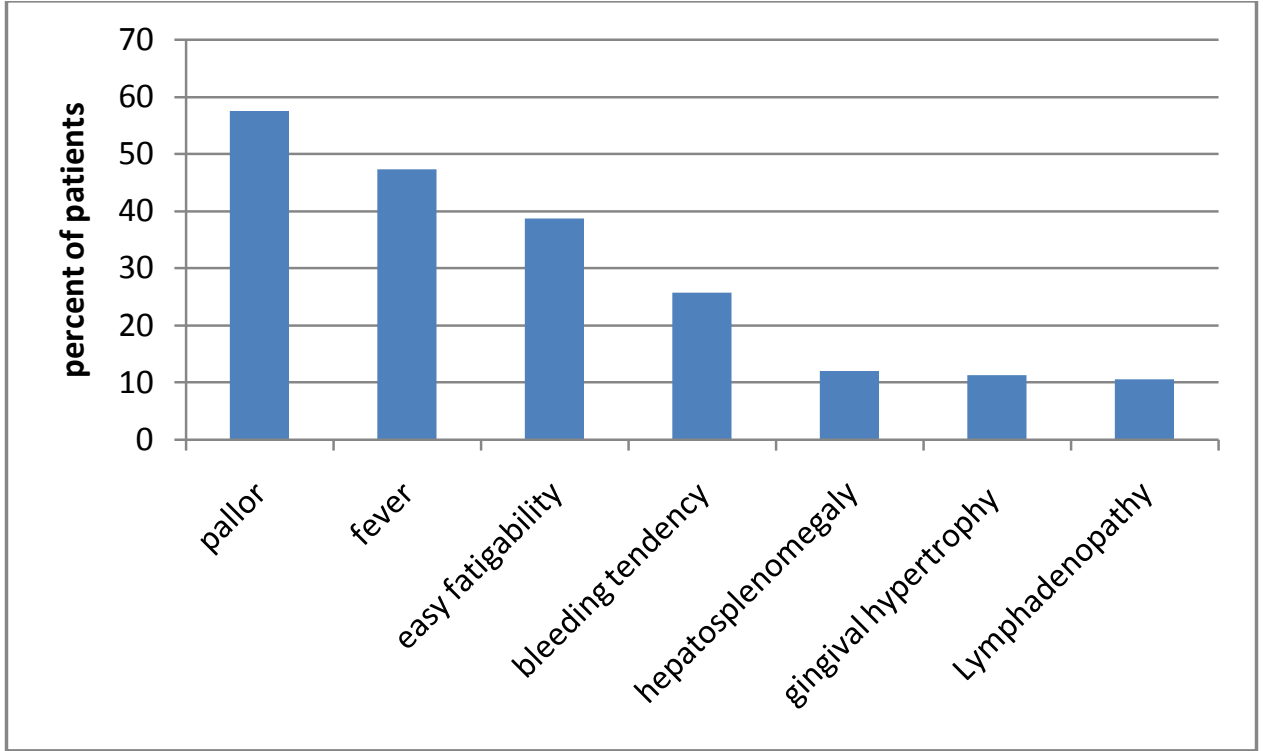

Figure 6:- Patient's common signs and symptoms.

\section{Aberrant CD56 and CD9 Expression:-}

CD56 was expressed in 7/30 patients (23.3\%), 3 of those were with moderateintensity, 2 were weak and 2 were strong. For CD9 expression, 10/30 patients(33.3\%) had positive expressions with 6 of those were with weak intensity, 2 were moderate and 2 were strong. And 2/30 patients (6.7\%) had CD56 andCD9 co expression (Figure 6).

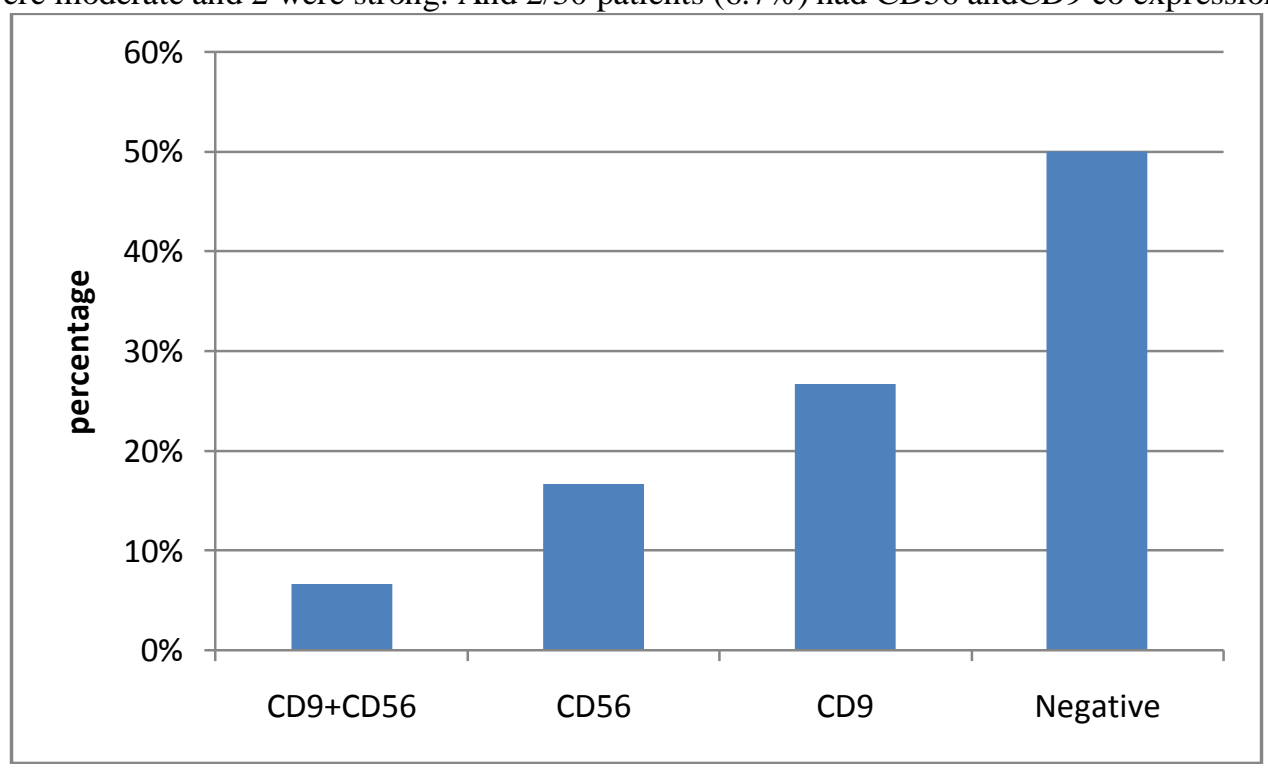

Figure 7:- Percentage of aberrant expression of CD56 and CD9 in AML patients.

Correlation between the aberrant $\mathrm{CD56}$ and $\mathrm{CD} 9$ expressions with hematological parameters:-

Table 2 shows that the total WBC count, PB and BM blast cells percentage of AML patients with aberrant CD56 expression were significantly higher than those without aberrant CD56 expression ( $p$ value $<0.05$ ), while there was nonsignificant correlation between $\mathrm{Hb}$ and platelet count with the aberrant CD56expression. 
Table 2:- Correlation between CD56 expression with hematological parameters.

\begin{tabular}{|l|l|l|l|l|l|}
\hline \multirow{2}{*}{ Parameter } & \multicolumn{2}{|l|}{ CD56 positive $(\mathbf{n}=7)$} & \multicolumn{2}{l|}{ CD56 negative $(\mathbf{n}=\mathbf{2 3})$} & P-value \\
\cline { 2 - 5 } & Mean & SD & Mean & SD & \\
\hline Total WBC $(\times 109 / \mathrm{L})$ & 88.9 & 18.8 & 16.5 & 17.7 & $<\mathbf{0 . 0 0 1}$ \\
\hline $\mathrm{Hb}(\mathrm{g} / \mathrm{dl})$ & 7.3 & 1.8 & 8.8 & 2.8 & 0.199 \\
\hline Platelet count $(\times 109 / \mathrm{L})$ & 82.3 & 43.1 & 53.7 & 35.7 & 0.088 \\
\hline PB blast cells \% & 68.2 & 54.6 & 30.6 & 10 & $<\mathbf{0 . 0 0 1}$ \\
\hline BM blast cells \% & 74.6 & 15.5 & 45.4 & 21 & $\mathbf{0 . 0 0 2}$ \\
\hline
\end{tabular}

Table 3. showed that there was no significant correlation between the aberrant CD9 expression and any of the hematological parameters.

Table 3:- Correlation between CD9 expression with hematological parameters

\begin{tabular}{|l|l|l|l|l|l|}
\hline \multirow{2}{*}{ Parameter } & \multicolumn{3}{l|}{ CD9 positive $(\mathbf{n}=\mathbf{1 0})$} & \multicolumn{3}{l|}{ CD9 negative $(\mathbf{n = 2 0})$} & P-value \\
\cline { 2 - 6 } & Mean & SD & Mean & SD & \\
\hline Total WBC $\left(\times 10^{9} / \mathrm{L}\right)$ & 25.7 & 34.3 & 37.2 & 36.8 & $\mathbf{0 . 4 2}$ \\
\hline Hb $(\mathrm{g} / \mathrm{dl})$ & 8.8 & 2.7 & 8.3 & 2.6 & 0.579 \\
\hline Platelet count $\left(\times 10^{9} / \mathrm{L}\right)$ & 64.4 & 33.2 & 58.4 & 42 & 0.699 \\
\hline PB blast cells \% & 36.1 & 19.7 & 41 & 18.3 & $<\mathbf{0 . 5}$ \\
\hline BM blast cells \% & 46.4 & 24.2 & 55.2 & 22.9 & $\mathbf{0 . 3 3 6}$ \\
\hline
\end{tabular}

The Distribution of aberrant CD56 and CD9 expression in relation to AML FAB Classification:-

CD56 was expressed in $57.1 \%$ of the cases of AML FAB subtypes withmonocytic differentiation (M5 cases (2/4, $50 \%$ ) and M4 (2/4, 50\%)); it was alsoexpressed in other FAB subtypes 1/4 for M1, 2/9 for M2. CD56 is not expressed on M3, M6 and M7 subtypes.

CD9 was expressed more in M2 subtype (4/9, 44.4\%). It is also expressed in all other AML subtypes except M7 subtypes

Correlation between the aberrant CD56 and CD9 expression withthe extramedullary manifestations:-

The extramedullary manifestations were present in $57.2 \%$ of CD56 positive patients with statistically significant correlation $(\mathrm{p}$-value $=0.016)$.

There is no significant correlation between CD9 aberrant expression and the extramedullary manifestations (p-value =1).

Correlation between the aberrant CD56 and CD9 expression with CRAchievement:-

Complete remission was achieved in $17 / 30$ patients $(56.7 \%)$ with standard chemotherapy. For patients with aberrant CD56 expression 6 out of 7 did notrespond to induction treatment. It appeared that there was a significant correlation between this expression with the non-responsiveness to the induction therapy with $\mathrm{p}$-value $=0.025$ (Table 4).

Table 4:- Correlation between aberrant CD56 expression with CR achievement

\begin{tabular}{|l|l|l|l|l|l|l|}
\hline \multirow{2}{*}{ CR achievement } & CD56 & Negative & \multirow{2}{*}{ Total } \\
\cline { 2 - 7 } & Positive & No. & \% & No. & \% \\
\cline { 2 - 7 } & No. & $\%$ & 16 & 69.6 & 17 & 56.7 \\
\hline Yes & 1 & 14.3 & 7 & 30.4 & 13 & 43.3 \\
\hline No & $\mathbf{6}$ & 85.7 & 23 & 100 & 30 & 100 \\
\hline & 7 & 100 & \multicolumn{5}{l}{} \\
\hline
\end{tabular}

For patients with aberrant CD9 expression 9 out of 10 did not respond toinduction treatment, and it appeared that there was significant correlationbetween this expression with the non-responsiveness to induction therapywith $\mathrm{p}$ value $<0.001$ (Table 5). 
Table 5:- Correlation between aberrant CD9 expression with CR achievement

\begin{tabular}{|c|c|c|c|c|c|c|}
\hline \multirow[t]{3}{*}{ CR achievement } & \multicolumn{4}{|c|}{ CD9 } & \multirow{2}{*}{\multicolumn{2}{|c|}{ Total }} \\
\hline & \multicolumn{2}{|c|}{ Positive } & \multicolumn{2}{|c|}{ Negative } & & \\
\hline & No. & $\%$ & No. & $\%$ & No. & $\%$ \\
\hline Yes & 1 & 10 & 16 & 80 & 17 & 56.7 \\
\hline No & 9 & 90 & 4 & 20 & 13 & 43.3 \\
\hline \multirow[t]{2}{*}{ Total } & 10 & 100 & 20 & 100 & 30 & 100.00 \\
\hline & \multicolumn{6}{|c|}{ P-value $<0.001$} \\
\hline
\end{tabular}

\section{Discussion:-}

This study was conducted on 30 newly diagnosed de Novo acute myeloidleukaemia patients. The mean age of all patients was $41.33 \pm 16.6 \mathrm{SD}$, medianof 38 years and ranged between $16-75$ years. Those results were comparable toIraqi studies (17-18).

Pallor and fever are the two most frequent signs, while Lymphadenopathyand gingival enlargement are the least frequent. Easy fatigability was the most frequent symptom. Those results were comparable to that published by AlwanAF et al. (19) and $\mathrm{Hu} \mathrm{R}$ et al. (20)Of the 30 cases studied, M2 was the most frequent AML subtype (30\%)followed by M3 (23.3\%). This result was comparable to studies done by PoulsRK et al. (21) in Erbil, Alwan AF et al. (19).

The current study revealed that CD56 was expressed in 7 cases out of 30(23.3\%) newly diagnosed AML cases, this result was in agreement withRaspadori D et al. (22) E et al. and Dina J et al. (23)

For CD9, it was expressed in 10 cases out of 30 (33.3\%) of AML cases. Thisresult is comparable to that obtained by El-Sissy AH et al. (24) who reported CD9expression in $29.4 \%$ of AML cases.

Regarding the haematological parameters; the total WBC count of AMLpatients with CD56 expression was significantly higher than those without thisexpression, those findings were comparable with the results obtained by OlteanuH et al. (25). Also the correlations were found betweenPeripheral blood (PB) and bone marrow (BM) blast cells percent of AMLpatients were significantly higher in patients with aberrant CD56 expression. The cause of the higher total WBC count, PB and BM blastcells percent in AML patients with CD56 expression may be explained by thatCD56 expression is associated with an abnormal over expression of the fulllengthp48 RUNX1 isoform in AML cells which block haematopoieticdifferentiation and enhances self-renewal of haematopoietic stem cells andthus we may predict that the CD56 is a poor prognostic marker.

For the distribution of aberrant expression among FAB subtypes, CD56 expression was expressed in half of the cases of AML FAB subtypes withmonocytic differentiation M5 cases $(2 / 4 ; 50 \%)$ and M4 (2/4; $50 \%)$ and thoseresults in agreement with Graf M et al. (26). The increased aberrant CD56 expression in M4 and M5 which areconsidered as unfavorable AML FAB subtypes (14) confirms that CD56 isassociated with a poor prognosis.

About the CD9 expression, it was detected more on M2 subtype (4/9;44.4\%). there was a significant correlation between CD56 expression and the extramedullary manifestations and this confirms also that CD56 is a poor prognostic marker as AML patients with increased extramedullary manifestations at presentation generally have a poor outcome. This result was in agreement with Chang $\mathrm{H}$ et al. (27)

On the other hand, CD9 expression was no significantly correlated with theextramedullary manifestations.

Regarding the initial response to the induction therapy, CD56 was highlyexpressed with the non-responsiveness to the induction therapy. This correlationmay be explained by observation of more frequent P-glycoprotein (PGP)expression in CD56 positive patients. 106). Those results were consistent with that of Raspadori D et al. (22)Regarding CD9 expression in this study was highly expressed with the non-responsivenessto the induction therapy. 


\section{Conclusion:-}

1. CD56 and CD9 expressions in AML patients were detected in 23.3\% and33.3\% respectively.

2. CD56 was expressed more in monocytic AML subtypes.

3. Aberrant CD56 expression was associated with a higher total WBC count, higher PB and BM blast cells, increased extramedullary manifestations atpresentation, and a lower response rate to the induction therapy; thus CD56can be considered as an unfavourable marker.

4. Aberrant CD9 expression was associated with lower response rate to the induction therapy; thus CD9 can be considered as an unfavorable marker.

\section{Recommendations:-}

1. Studying the correlation of the aberrant expression of CD56 with multidrug related P-glycoprotein (PGP).

2. Studying further aberrant antigens expression in AML as CD10, CD22, and CD4.

3. Further studies for CD9 expression in AML patients.

4. The study should be performed on larger sample size and for longer period of time.

\section{References:-}

1. Shipley JL and Butera JN. Acute myelogenous leukemia. ExpHematol2009;37:649-58.

2. Deschler B , Lübbert M. Acute myeloid leukemia: epidemiology andetiology. Cancer 2006; 107(9): 20992107.3.

3. Akagi T, Ogawa S, Dugas M, et al. Frequent genomic abnormalities in acute myeloid leukemia/myelodysplastic syndrome with normal karyotype. Haematologica 2009; 94(2): 213-223.

4. Bain BJ. Classification of acute leukaemia: the need to incorporate cytogenetic and molecular genetic information. J ClinPathol 1998; 51: 420- 423.

5. Behm FG. Classification of acute leukemias. Available at:www.springer.com/cda/.../9780896038349-c2.pdf (accessed on 4 Oct 2015).

6. Zuckerman T, Rowe JM. Acute leukaemia. In: Schmaier AH, LazarusHM,editors. Concise Guide to Hematology. First edition: Wiley Balckwell;2012; 19: 235-250.

7. Döhner H, Estey EH, Amadori S et al. Diagnosis and management of acutemyeloid leukemia in adults: recommendations from an international expertpanel, on behalf of the European Leukemia Net. Blood 2010; 115(3): 453-474.

8. Bain BJ, Swirsky D. Erythrocyte and leucocyte cytochemistry. In: Bain BJ,Bates I, Laffan MA et al. editors. Dacie and Lewis practical hematology. $11^{\text {th }}$ ed. Philadelphia: Churchill Livingstone Elsevier 2011; 15: 333-352.

9. Naeim F, Rao PN. Acute myeloid leukemia. In: Naeim F, Rao PN, GrodyWW, editors. Haematopathology: morphology, immunophenotype, cytogenetic, and molecular approaches. Oxford: Elsevier Inc 2008; 11: 207251.

10. Orfao A, Ortuno F, Santiago M, et al. Immunophenotyping of acuteleukemias and myelodysplastic syndromes. Cytometry Part A 2004; 58A: 62-71.

11. Legrand O, Perrot JY, Baudard M, et al. The immunophenotype of 177adults with acute myeloid leukemia: proposal of a prognostic score. Blood 2000;96(3): 870-877.

12. Immunophenotyping and cytogenetic/molecular genetic analysis in leukemiaand related conditions. Barbara J. Bain, Leukemia diagnosis. Fourth edition.Hong Kong. Wiley-Blackwell 2010; 64-107.

13. Hemler ME. Tetraspanin proteins mediate cellular penetration, invasion, andfusion events and define a novel type of membrane microdomain. Annu Rev CellDevBiol 2003; 19:397-422.

14. Reyes AA, Small SJ, Akeson R. "At least 27 alternatively spliced forms ofthe neural cell adhesion molecule mRNA are expressed during heartdevelopment". Molecular and Cellular Biology 2011; (3): 1654-1661.

15. Sysmex. CyFlow ${ }^{\circledR}$ Cube 6. Available at:

16. http://www.sysmexpartec.com/instrumentation/products.html?\&tx_cyclosproductfinder_cyc_pf_dis

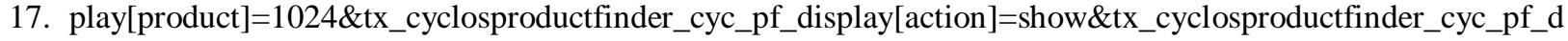
isplay[controller] $=$ Product (accessed 20 Feb2016).

18. Berditchevski F. Complexes of tetraspanins with integrins: More than meetsthe eye. J Cell Sci 2001; 114:41434151.

19. Dhahir EK. The Significance of FLT3-ITD Mutation and NucleophosminMutation in Acute Leukemia. A thesis Submitted to the College of Medicine -Al Nahrain University in Partial Fulfillment of the Requirement for the Degreeof Doctor of Philosophy in Pathology (Hematology) 2012.

20. Gari M., Abuzenadah A., Chaudhary A., et al.: Detection of FLT3 OncogeneMutations in Acute Myeloid 
Leukemia Using Conformation Sensitive GelElectrophoresis .Int. J. Mol. Sci 2008; 9: 2194-2204.

21. Alwan AF, Zedan ZJ, Salman OS. Acute myeloid leukemia: clinical featuresand follow-up of 115 Iraqi patients admitted to Baghdad Teaching Hospital.Tikrit Medical Journal 2009; 15(1): 1-8.

22. Hussein SH. Survey of Adult de novo Acute Myeloid Leukemia cases reportedin the Medical City in Baghdad through the years (2005-2011). A thesisSubmitted to the College of Medicine -University of Baghdad in PartialFulfillment of the Requirement for the Degree of Master of Hematology 2013.

23. Pouls RK, Shamoon RP, Muhammed NS. Clinical and haematologicalparameters in adult AML patients: a four year experience at NanakalyHospitalfor blood diseases. Zanco J Med Sci 2012; 16(3): 199-203.

24. Raspadori D, Damiani D, Lenoci M, et al. CD56 antigen expression in acutemyeloid leukemia identifies patients with poor prognosis. Leukemia.2001;15:1161-1164

25. Dina J, Salaün V, Reman O, et al. Interest of immunophenotyping in acutemyeloid leukemia. Haematologica 2002; 87: 14-15.

26. El-Sissy AH, El-Mashari MA, Bassuni WY et al. Aberrant lymphoid antigenexpression in acute myeloid leukemia in Saudi Arabia. Journal ofthe Egyptian Nat. Cancer Inst 2006; 18(3): 244-249.

27. Olteanu H, Harrington AM, Kroft SH, et al. The incidence of CD56 expressionby flow cytometry in acute promyelocytic leukemia in patients treated with alltransretinoic acid and anthracycline drug combinations. Available at:http://pathology.mcw.edu/blog/the-incidence-of-cd56-expression/ (accessed 7

28. August 2014).

29. Graf M, Reif S, Hecht K, et al. High expression of costimulatory moleculescorrelates with low relapse-free survival probability in acute myeloid leukemia(AML). Ann Hematol 2005; 84(5): 287-297.

30. Chang H, Brandwein J, Qi-Long yi, et al. Extramedullary infiltrates of AMLare associated with CD56 expression, 11q23 abnormalities and inferior clinicaloutcome. Leukemia Research 2004; 28(10): 1007-1011. 